\author{
Cadernos de \\ ESTUDOS LINGUIISTICOS - (59.3), Campinas, pp. 519-535 - set./dez. 2017
}

\title{
REVISITANDO A PALAVRA PROSÓDICA NO PORTUGUÊS BRASILEIRO
}

\author{
PRISCILA MARQUES TONELI* \\ (UNICAMP)
}

\begin{abstract}
RESUMO: Este artigo apresenta uma definição para o domínio da Palavra Prosódica (PW) no Português Brasileiro (PB). Para cumprir esse objetivo, eu reviso os principais trabalhos realizados no PB sobre a fonologia da palavra e o referencial teórico utilizado para a definição de PW. Na sequência, discuto os fenômenos fonológicos que podem tomar a PW como domínio de aplicação e aqueles que podem funcionar como diagnósticos para identificá-la e/ ou caracterizá-la. Por fim, analiso a prosodização de palavras funcionais e de palavras lexicais, incluindo os afixos átonos, em relação ao comportamento prosódico como sílabas átonas ou como PWs.

Palavras-chave: Fonética-Fonologia; Acento; Palavra Prosódica.
\end{abstract}

ABSTRACT: This paper aims to present a definition for Prosodic Word domain in Brazilian Portuguese. In order to achieve this, I perform a literature review of the main works in the area of phonology of the word in BP, and their theoretical references for the PW definition. Next, I discuss the phonological phenomena that can take PW as the domain of application and those that can function as diagnostics to identify and/or characterize it. Finally, I present the prosodization of functional words and lexical words, including the unstressed affixes, in relation to prosodic behavior as unstressed syllables or as PWs.

Keywords: Phonetics-Phonology; Stress; Prosodic Word.

\section{O. INTRODUÇÃO}

Este artigo homenageia a professora Maria Bernadete Marques Abaurre pelos seus anos de dedicação aos estudos linguísticos enquanto docente titular da Universidade Estadual de Campinas e orientadora de vários trabalhos acadêmicos, dentre os quais, incluo os trabalhos que por mim foram desenvolvidos enquanto orientanda de mestrado e de doutorado.

Dentre esses trabalhos, a linha de pesquisa por mim seguida se insere nos estudos relacionados à fonologia da palavra, um dos temas em que a Bernadete tanto se dedicou nesses anos de pesquisa. Em vista disso, o presente artigo tem como objetivo definir o domínio da Palavra Prosódica (PW - Prosodic Word) no Português Brasileiro (doravante $\mathrm{PB}$ ) a partir de uma revisão das minhas pesquisas de mestrado de 2009 e de doutorado de 2014 e trabalhos desenvolvidos durante esse período.

* Graduada em Licenciatura em Letras pela UNESP-RIO PRETO (2004), Mestrado e Doutorado em Linguística pela UNICAMP. pmtoneli@gmail.com 
Para cumprir esse objetivo, retomo a definição de PW, na seção 1, conforme propõe Nespor \& Vogel (1986) e alguns trabalhos que já trataram do respectivo domínio no PB. Na seção 2, apresento a análise dos processos fonológicos que servem como evidência e caracterizam a formação desse domínio conforme a teoria de domínios prosódicos (SELKIRK, 1984; NESPOR E VOGEL, 1986; HAYES, 1989; VIGÁRIO, 2003, 2007), destacando a prosodização de afixos na formação da PW e do comportamento prosódico de palavras funcionais. ${ }^{1}$

Na seção 3, discuto a prosodização de palavras lexicais e de palavras funcionais (monossilábicas e dissilábicas) como PW(s) ou como sílabas átonas para propor uma definição de PW no PB, e, por fim, na seção 4, faço as considerações finais sobre o presente artigo e destaco encaminhamentos de pesquisa relativas a questões que ficaram abertas no desenvolvimento de meus trabalhos e que fazem referência não só a esse domínio no $\mathrm{PB}$, mas a outros domínios mais altos da hierarquia prosódica.

\section{A PW NATEORIA DE DOMÍNIOS PROSÓDICOS E NA LITERATURA DO PB}

$\mathrm{Na}$ presente seção, apresento uma definição teórica para o domínio PW a partir dos pressupostos da Fonologia Prosódica conforme a proposta de Nespor e Vogel (1986). Essa teoria propõe que as línguas têm uma estrutura prosódica que é formada por constituintes prosódicos que são universais e que servem de domínio para a aplicação de regras fonológicas específicas (SELKIRK, 1982, 1984, 1986; NESPOR e VOGEL, 1986).

Nesse caso, a PW é considerada um dos menores constituintes da hierarquia acima da sílaba e do pé e é construída com base em regras de mapeamento da cadeia segmental que fazem uso de noções não fonológicas, podendo ocorrer o reajuste das sílabas $(\sigma)$ e os pés $(\Sigma)$, quando necessário, dentro do domínio de PW, desde que sejam respeitados os princípios universais e as restrições específicas da língua.

\footnotetext{
${ }^{1}$ Neste trabalho, considero como palavra funcional aquela que pertence a categoria funcional que por sua vez é definida como: composta por núcleos de classes fechadas, fonologicamente dependentes por conta da ausência de acento primário, tem um único complemento e não tem um argumento, além de ser sem 'conteúdo descritível', com presença de traços gramaticais. Essa categoria inclui as preposições, os artigos, as conjunções e os pronomes, pois tais palavras não derivam de um radical que pode originar outra categoria como o verbo, o substantivo e o adjetivo, ou seja, não permitem a criação de novos termos pelos falantes (cf. Cook \& Newson, 1996; Mioto et al, 2004).
} 
Com relação ao mapeamento morfologia/fonologia, algumas línguas mostram que PW e palavra morfológica podem ser (i) do mesmo tamanho - isomórficas, (ii) menores ou (iii) maiores que o nó sintático terminal (cf. NESPOR e VOGEL, 1986). No caso do PB, Bisol (2004) mostra que o nó sintático terminal pode incluir as três opções: equivaler a uma PW [[prefIxo $\left.]_{P W}\right]_{W}{ }^{2}$ ser maior $\left[[d e]_{W}[s E d a]_{W W}\right]_{P W}$ ou ser

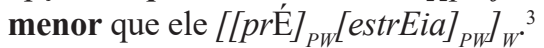

Em vista disso, Nespor e Vogel (1986), de modo a incluir todas as opções disponíveis nas línguas, reuniram todas as possibilidades para a definição de PW e formularam a definição geral dada abaixo:

(1) $\omega$ domain: ${ }^{4}$

A. The domain of $\omega$ is $Q$. or

B. I. The domain of $\omega$ consists of: a. stem; b. any element identified by specific phonological and/or morphological criteria; c. any element identified by specific phonological and/ or morphological criteria.

II. Any unattached elements within $\mathrm{Q}$ form part of the adjacent $\omega$ closest to the stem; if no such $\omega$ exists, they form a $\omega$ on their own.

É importante ressaltar que essa definição tem sido revista e refinada, principalmente em relação ao fato de algumas palavras funcionais formarem PWs independentes (cf. PEPERKAMP, 1997; VIGÁRIO, 2003; TONELI, 2009, 2014), por exemplo preposições como contra e desde, mesmo não formando sozinhas um nó sintático terminal.

Apresentada a definição teórica de PW que norteia o presente estudo, retomo alguns trabalhos que abordaram a fonologia da palavra no $\mathrm{PB}$, direta $\mathrm{e}$ indiretamente. Dentre esses trabalhos, serão destacados apenas os estudos de Câmara Jr (1969, 1975), Leiria (2000), Bisol (2004) e Toneli (2009; 2014), embora as referências aos meus trabalhos serão feitas ao longo de todo o artigo.

Câmara Jr $(1969 ; 1975)$ é o primeiro que reflete sobre o domínio da PW na variedade brasileira ao distinguir a palavra morfológica do vocábulo fonológico, o qual é denomino como PW no presente artigo, embora não seja objetivo do autor explorar sistematicamente a definição e a caracterização desse domínio na variedade brasileira.

${ }^{2}$ Usamos o símbolo W para indicar palavra morfológica. O símbolo $\omega$ e a sigla PW indicam o termo palavra prosódica que é usado como sinônimo de palavra fonológica, outro termo usado na literatura para o domínio prosódico que estudo.

${ }^{3}$ A maiúscula nos exemplos apresentados ao longo deste artigo indica vogal acentuada por acento primário.

${ }^{4}$ Domínio de palavra prosódica (PW): O domínio de PW é Q $(\mathrm{Q}=$ nó sintático terminal). Ou I. O domínio de PW consiste de: (a) uma raiz; (b) algum elemento identificado por critérios morfológicos e/ou fonológicos específicos; (c) algum elemento marcado com o diacrítico [+W]. II. Quaisquer elementos soltos dentro de Q faz parte da PW adjacente mais próxima da raiz. Se nenhuma palavra existir, eles formam uma PW por conta própria Nespor e Vogel (1986, p. 141, tradução minha). 
Câmara Jr. propõe, para identificar o vocábulo fonológico, uma pauta prosódica, atribuindo um 3 a uma sílaba tônica mais à direita ( por exemplo em palavras compostas como em guArda-costas) e 2 às sílabas que carregam o acento primário (por exemplo, o acento primário associado ao primeiro vocábulo fonológico em guArda, os quais ele chama de 'acentos fortes'), 1 para uma sílaba pretônica (que poderia corresponder a um acento secundário), e 0 para sílabas átonas postônicas (que correspondem a sílabas não acentuadas).

Diferentemente de Câmara Jr, Leiria (2000) faz referência direta ao domínio da PW, mostrando que esse constituinte faz parte da hierarquia prosódica do $\mathrm{PB}$ a partir da aplicação da regra de neutralização da pretônica dentro de PW, por exemplo, em caf $[\varepsilon]>$ caf [e]tEIra, e da aplicação de queda silábica entre fronteiras de palavras em ambiente $\mathrm{C}_{1} \mathrm{~V}_{1} \mathrm{C}_{2} \mathrm{~V}_{2}$, como em cAnto tOnal $\sim c A n[t$ :]Onal, fenômeno conhecido na literatura como haplologia ${ }^{5}$. Esse fenômeno interssilábico apaga $\mathrm{C}_{1} \mathrm{~V}_{1}$ quando ocorre uma sequência de duas sílabas semelhantes, como exemplificado acima.

Para Leiria, a ocorrência da haplologia na fronteira de PW atende a um requisito básico para justificar a existência de uma categoria prosódica que é ser domínio para a ocorrência de regras fonológicas, como também afirma Booij (1996). A autora busca, inicialmente, caracterizar o domínio PW no PB, no entanto limita sua pesquisa aos fenômenos segmentais, não incluindo fenômenos entoacionais, como proponho em minha tese (TONELI, 2014), tampouco em discutir uma proposta de prosodização a palavras funcionais, como faço em minha dissertação de mestrado (TONELI, 2009).

Dentro da perspectiva de Leiria em mostrar evidências do domínio PW no PB, Bisol (2004) avança ao discutir a interação entre as unidades morfológica e fonológica, focando na dimensão e nas funções da PW no PB. Baseando-se nos algoritmos de construção de constituintes prosódicos propostos por Nespor e Vogel (1986), Bisol apresenta evidências desse domínio no PB, afirmando primariamente que a condição mínima para se estabelecer uma PW é a unidade seja dotada de apenas um acento primário.

Quanto à dimensão de uma PW, no PB, Bisol afirma que a isomorfia entre palavra morfológica e PW nem sempre se mantém e exemplifica isso com o comportamento de prefixos que ora são prosodizados como sílabas átonas, ora como PWs, por exemplo, em $\operatorname{pr}\left[\varepsilon_{\varepsilon}\right]+f I x o=\operatorname{pr}[e] f I x o$ quando ocorre o alçamento da vogal média / $\varepsilon$ / do prefixo pré em posição pretônica, transformando o prefixo em sílaba pretônica. Na palavra composta pr[É]-estrÉia, o fato de a vogal do prefixo prÉ manter-se média baixa é uma evidência do acento primário no prefixo e da prosodização deste como PW independente. Nesse segundo caso, conforme a definição de Nespor \& Vogel (1986), o prefixo é exemplo de que essa PW é menor que o elemento terminal de uma árvore sintática que no caso é uma palavra derivada formada por duas PWs (cf. BISOL, 2004).

Bisol explica que, quando há a ressilabificação em que a segunda palavra inicia por vogal, como em lÁpis Azul, a PW pode ser maior do que o elemento terminal de uma árvore sintática, já que, nesse contexto, ocorre, após o vozeamento

${ }^{5}$ Definição proposta por Alkmim e Gomes (1982). 
da fricativa surda /s/ ao entrar em contato com a vogal da palavra seguinte, a ressilabificação. Nesse caso, a coda da primeira palavra lÁpis passa a onset da sílaba seguinte /'la.pi.za. 'zul/ dentro do mesmo Q.

Em relação às funções da $\mathrm{PW}$, Bisol destaca (i) ser portadora de proeminência relativa, ou seja, a PW tem apenas uma sílaba proeminente em relação às outras sílabas; (ii) ser domínio de aplicação de regras fonológicas, como exemplo, a regra de neutralização das átonas finais, a harmonia vocálica e o abaixamento datílico, entre outras; e (iii) ser o domínio de restrições fonotáticas, por exemplo, consoantes palatais como $/ K /$ não podem iniciar PW. Destaco que Bisol não se propõe a definir a $\mathrm{PW}$ no $\mathrm{PB}$, tampouco extrapola seu estudo aos fenômenos entoacionais que podem caracterizar tal domínio.

Por fim, a proposta de meus trabalhos é ampliar e complementar os estudos anteriores (TONELI, 2009, 2014) na medida que sistematizo os fenômenos fonológicos que identificam e caracterizam o domínio PW no PB. Para isso, discuto como as palavras morfológicas, lexicais e funcionais, são prosodizadas em termos de PW ou de sílabas átonas, incluindo nessa sistematização fenômenos entoacionais que até então não foram reportados na literatura como evidências da PW ou como meios de diagnosticá-la, além de propor uma definição para esse domínio na variedade brasileira (TONELI, 2014). As minhas contribuições serão sintetizadas e discutidas a seguir nas próximas seções.

\section{FENÔMENOS FONOLÓGICOS QUE DIAGNOSTICAM E CARACTERIZAM A PW NO PB}

Tem sido reportado na literatura que todas as línguas possuem um conjunto de diagnósticos que são comuns para a identificação de uma PW e que caracterizam esse domínio prosódico, prosodizando determinados elementos morfológicos em sílabas átonas ou em PWs independentes e ajudando na delimitação das fronteiras de PW. Na presente seção, discuto alguns desses fenômenos que são relevantes para a caracterização dos limites de PW no PB e destaco se esses fenômenos diagnosticam o comportamento prosódico de afixos e de palavras funcionais como sílabas átonas ou como PWs.

Dentre eles, a regra de atribuição de acento primário é o principal fenômeno para a identificação da PW no PB (e no português de modo geral), já que a presença de um acento, seja num prefixo, seja numa palavra funcional, é evidência de que o item se comporta como PW independente e não como sílaba átona. É importante destacar que o presente estudo parte da premissa de que todo radical lexical que constitui uma palavra morfológica e que recebe acento primário é prosodizado como PW. Por isso a discussão na presente seção focará nos elementos que geram controvérsias na literatura, no caso os afixos e as palavras funcionais. ${ }^{6}$

${ }^{6}$ Não será discutido o comportamento de palavras morfológicas compostas por duas palavras portadoras de acento primário, como no caso de guArda-chUva, pois esse tipo de palavra morfológica extrapola os limites da definição que proponho aqui. 
Em relação a essa regra no português, é notado que ela respeita a janela de três sílabas da direita à esquerda para localização do acento primário, como em jacarÉ, caRÁter e PÊssego, que pode incidir também em palavras monossilábicas, como em $r E ́$, formando uma PW, já que o português, de modo geral, não sofre a síndrome da palavra mínima (cf. BISOL, 2000; VIGÁRIO, 2003). Desse modo, nem o tamanho da palavra (apenas uma ou mais de uma sílaba) nem o tipo de sílaba que é acentuada (leve ou pesada) influenciam a formação do domínio da PW no PB.

Logo, a síndrome da palavra mínima não é diagnóstico para a prosodização de prefixos e de palavras funcionais monossilábicas como PWs, mas sim a presença de acento primário em uma dada unidade morfológica implica que essa unidade tem o estatuto de PW, consequentemente identificando uma PW.

Em relação aos sufixos do português, grande parte deles têm em comum, conforme descrito na literatura, o fato de constituírem, com a base a que se unem, uma única PW, uma vez que são os alvos de receber acento primário durante a aplicação de tal regra. Isso porque a adição de um sufixo a uma base lexical influencia na posição do acento de palavra, que se desloca mais à direita, respeitando a janela acentual do português que é de três sílabas da direita à esquerda. Nesse caso, o acento primário recai sobre uma das vogais do sufixo como em CAnto + ada $>$ cantAda, aLISta + mento $>$ alistamEnto, sOnho + ar $>$ sonhAr e contÁbil + idade $>$ contabilidAde.

Sendo a presença de acento primário o principal diagnóstico para a identificação de uma PW nas línguas em geral, a sua ausência, portanto, também diagnostica uma palavra funcional como sílaba(s) átona(s). Nesse sentido, Bisol (2000, 2005) e Toneli (2009) mostraram para o PB que a categoria funcional apresenta comportamento prosódico semelhante ao de outras línguas, já que algumas palavras funcionais monossilábicas não formam nó sintático terminal e, tampouco, domínios independentes para a atribuição de acento primário.

Ressalto, entretanto, que há palavras funcionais dissilábicas, trissilábicas e até monossilábicas que preenchem essa condição, recebendo, portanto, acento primário, por exemplo, algumas preposições como dEsde e perAnte, conjunções, como entretAnto, todavIa e porÉm, e pronomes, como EU, Este e aquIlo. Esse comportamento prosódico é corroborado não só pela presença de acento primário, mas também por tais palavras não sofrerem fenômenos fonológicos típicos de sílabas átonas, como discuto a seguir.

Em relação ao papel das generalizações fonotáticas no português, Bisol (2000) e Vigário (2003) afirmam que a PW é domínio para tais restrições, uma vez que não há $\mathrm{PW}$ que inicie por alguns segmentos, por exemplo, consoantes palatais $/ \mathrm{\eta}, \Lambda /$ e tepe /r/, exceto no caso de empréstimos como nhOque e lhAma, embora possam aparecer iniciando sílabas internas dentro de PW, como em mAlha, manhÃ e cAro. No caso da palavra funcional lhe, seu caráter átono é justificado por ferir uma generalização fonotática da língua do domínio de PW (cf. BISOL, 2005; VIGÁRIO, 1999, 2003).

Dentre os processos segmentais que funcionam como os diagnósticos para a identificação de uma $\mathrm{PW}$ no $\mathrm{PB}$, a regra de redução vocálica da pauta tônica a cinco vogais, quando em posição pretônica, e a três vogais, quando em posição postônica é o fenômeno fonológico que fortifica a análise da prosodização de palavras funcionais e afixos como sílabas átonas ou como PW. 
Em uma palavra como lógica, a sílaba tônica é a primeira à esquerda, a qual tem como núcleo uma vogal média baixa posterior / $/$ que ocorre normalmente em posições tônicas. Entretanto, em palavras derivadas com a mesma base lexical logic-, como em l[o]giCISmo, após o acréscimo do sufixo -ismo, a sílaba acentuada passa a ser a penúltima e a vogal da primeira sílaba à esquerda, que antes portava o acento primário, em lógica, é elevada a média alta /o/, pois se torna uma sílaba pretônica.

Essa regra ainda explica o comportamento de alguns prefixos como sílabas pretônicas e não como PWs, como é observado em palavras como pr[e]concEIto, mas não em $\operatorname{pr}[\varepsilon]$-escOla. Ressalto que essa regra ocorre apenas dentro dos limites da interação entre palavra morfológica e PW, não servindo de argumento para o comportamento de palavras funcionais.

Outro fenômeno que ocorre em sílabas pretônicas é a harmonia vocálica dentro de uma PW. A literatura mostra que a harmonia é dependente das características da vogal da sílaba tônica, por exemplo, em $p[e] p I n o \sim p[i] p I n o, p[\varepsilon] r[\varepsilon] r[\varepsilon ́] c a$ e $c[\supset] l[\hat{\varepsilon}] g a$. Contudo, esse tipo de processo fonológico parece ocorrer em algumas variedades específicas de PB e é dependente da vogal tônica.

A harmonia também é um fenômeno restrito aos limites da PW enquanto esta interage com os limites da palavra morfológica, não incluindo palavras funcionais átonas, ou seja, em sequências como me $l / \hat{\varepsilon} / v a$ os traços da vogal do verbo não se harmonizam com a vogal do pronome em $* m / \mathcal{E} / l / \varepsilon / v a$. Esse fato é evidência de que palavras funcionais não se comportam como sílabas pretônicas de uma palavra lexical, pois não sofrem fenômenos fonológicos típicos dessas sílabas.

Em relação às posições postônicas, a redução da pauta vocálica se resume em três vogais /i, u, a/, já que as vogais /e, o/ são normalmente produzidas como $[I, U]$, respectivamente, como em $d A d[o] \sim d A d[v]$ e $\operatorname{grEv}[e] \sim \operatorname{grEv}[I]$, fenômeno inicialmente já notado por Câmara Jr (1970) que se estende a todas as variedades faladas no Brasil.

De modo geral, no caso de palavras funcionais, para afirmar que se comportam como sílabas átonas e não como PWs, a pista da ausência de acento é a regra de redução da pauta vocálica de cinco $[\mathrm{e}, \mathrm{i}, \mathrm{o}, \mathrm{u}, \mathrm{a}]$ a três vogais $[I, U]$, em [o] menIno $\sim[v]$ minIno, $d[e] \operatorname{manh} \tilde{A} \sim d[I]$ manh $\tilde{A}$ e $d[a]$ menIna.

No caso das palavras funcionais, não é possível interpretá-las como sílabas pretônicas ou postônicas, pois como afirmado acima, não sofrem fenômenos típicos dessas sílabas. Todavia, por sofrer a elevação/alçamento das vogais médias altas /e, o/ a vogais altas [I, $U$ ], tal fenômeno é usado como evidência da ausência de acento primário e como diagnóstico de que algumas palavras funcionais, destacadas a seguir, se comportam prosodicamente como sílabas átonas:

(2) Palavras funcionais com [I]: de, me, te, se, lhe(s), que, em, porque, e, se, que

Palavras funcionais com [u]: o(s), com, do(s), no(s), nos, vos, por, porque 
No caso de algumas palavras funcionais, há ainda outros fenômenos que corroboram o comportamento átono delas, por exemplo, a preposição 'com' pode perder o traço de nasalidade e há a degeminação (doravante DG) das vogais em sequências com duas palavras funcionais, como com $+o \sim c o$ e em com $+a \sim c a$. Pode ocorrer ainda a formação de um ditongo com o artigo com $+a \sim c \hat{a} a \sim$ cua. Esses fenômenos não ocorrem em palavras lexicais como dom e som, quando seguidas por artigo, $d \mathrm{Om}+a *$ [da] ou $\mathrm{SOm}+a *[\mathrm{sa}]$.

Outra palavra funcional que merece destaque é a preposição dissilábica para, visto que, por ser dissilábica, forma um pé e poderia receber acento primário. Todavia, trabalhos sobre o PB (BISOL 2000, 2005; TONELI, 2009, 2014) têm mostrado formas reduzidas produzidas na fala oral, como pra e pa, além de haver formas contraídas com artigos como para + um $>$ prum, para $+o>$ pro, pó, e até mesmo em textos escritos. Esses fatos mostram que tal preposição sofre, além de redução vocálica, a regra de apagamento vocálico da vogal que poderia receber acento primário. Esses fatos mostram que tal palavra apresenta comportamento de sílaba átona assim como ocorre nas sílabas postônicas de uma palavra lexical como fósforo $\sim f O ́ r f i \sim f O ́ s f r u$.

Outro processo fonológico que não afeta vogais acentuadas é a semivocalização, pois, conforme afirma Vigário (2003), a não aplicação de tal fenômeno, principalmente a palavras monossilábicas é evidência de que tal palavra constitui uma PW, como pode ser em observado em $d \hat{E}$ abrAços $[\mathrm{e}] / *[\mathrm{j}] / * 0^{7}$ e $p O ́$ amarElo [o]/*[u]/*[w]/*0. Nesses casos, a vogal acentuada não é transformada em semivogal quando se encontra com outra vogal em contexto interssilábico, como ocorre em $p A[w]$ amarElo.

Em relação a algumas palavras funcionais como a conjunção $e$, o artigo $o$ e a preposição $d o$, a semivocalização é evidência de que tais palavras são sílabas átonas, já que as atingem, como pode ser observado em blUsa Azul [e] amarEla > blUsa Azul [ja]marEla, querIa ver [o] animAl > querIa ver [wa]nimAl, e a pEle $d[o]$ animAl $>$ a pEle $d[$ wa]nimAl.

A formação de um ditongo entre as vogais das palavras funcionais e as vogais das palavras lexicais que seguem ou antecedem e a semivocalização são evidências do caráter átono das palavras funcionais analisadas, mostrando que esse fenômeno prosódico pode ajudar a caracterizar e diagnosticar uma PW no PB.

Em relação à elisão da vogal que é núcleo silábico, enquanto isso não afeta sílabas acentuadas de palavras lexicais, corrobora o caráter átono de palavras funcionais como a preposição com seguida por artigo, como em com + a MarIa = [ka]MarIa. Nesse caso há o apagamento não só da vogal da preposição com, que é o núcleo da sílaba, mas do traço de nasalidade da preposição.

Destaco que a elisão pode apagar a vogal semivocalizada em posição de coda da sílaba como em pEixe $\sim$ pexe e Ouro $\sim$ oro, não afetando, portanto, a vogal núcleo da sílaba.

${ }^{7} \mathrm{O}$ zero indica apagamento de determinado segmento, enquanto o asterisco indica que determinado fenômeno fonológico não ocorre. 
Outro fenômeno fonológico que ocorre nos limites de PW e pode servir como diagnóstico de tal domínio é a regra de assimilação fonética de nasalidade pela vogal /a/ que ocorre quando a vogal assimila a nasalidade fonética da nasal da sílaba seguinte, como em $c A n a \sim c \tilde{A n} a$ e arAnha $\sim$ arÃnha. Essa regra tem sido descrita na literatura como um processo variável que não ultrapassa os limites de $\mathrm{PW}$, exceto, eventualmente, quando há ressilabificação com alguns prefixos em que a nasalidade em final de palavra torna-se onset da sílaba seguinte, como em pan+americAno > pã.na.me.ri.cA.no. Nesse caso, o traço de nasalidade preenche o onset da sílaba seguinte no processo de ressilabificação, embora a vogal do prefixo mantenha o traço de nasalidade (BISOL, 2004).

Esse processo, sobretudo, não ocorre entre $\mathrm{PWs}$, como afirmado por Abaurre e Pagotto (1996, 2013), como em cArro nOvo $\sim{ }^{*}$ cArrõ nOvo e rApidamEnte *rApidãmEnte e também não afeta a sequência palavra funcional e palavra

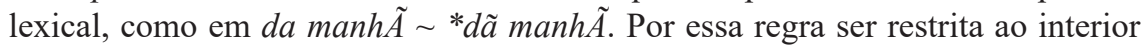
de PW, é, portanto, um bom diagnóstico para identificá-la, além de uma evidência caracterizadora de tal domínio no PB.

Um último fenômeno segmental já apontado na literatura por Leiria (2000) como caracterizador de PW no PB e por Vigário (2003) para o PE é a haplologia. Embora esse processo não tenha aplicação apenas entre PWs, pois ocorre entre as fronteiras de domínios mais altos como do sintagma fonológico $(\varphi)$ e do sintagma entoacional (I), como mostrado por Tenani (2002), vale lembrar que é um fenômeno que identifica a PW, já que respeita os limites dela, ocorrendo apenas entre PWs, como em faculdAde dinÂmica $<$ faculdAdinÂmica, não ocorrendo dentro de uma única PW, como em bebedEIra < *bedEIra.

Discutidos os processos fonológicos segmentais que identificam e diagnosticam uma PW, além de caracterizá-la como domínio de aplicação de regras fonológicas, há alguns fenômenos suprassegmentais, além da regra de acento primário já apresentada no início da presente seção, que contribuem na identificação de uma PW no PB, mais especificamente fenômenos entoacionais, como o acento tonal (pitch accent - PA, termo do inglês) e o evento tonal associado às sílabas pretônicas iniciais de $\mathrm{PW}$, e outros fenômenos acentuais, como o acento secundário e o acento enfático.

Trabalhos como os de Collischon (1993, 1994), Abaurre e Sandalo (2007), Fernandes-Svartman (2009) e Abaurre e Fernandes-Svartman (2008) têm mostrado que o acento secundário é atribuído a sílabas pretônicas de uma $\mathrm{PW}$, seguindo uma métrica a partir da posição do acento primário. O que interessa na presente discussão é que esse acento não ultrapassa os limites da PW no PB, sendo, então, um bom diagnóstico para sua identificação, além de ser um fenômeno que a caracteriza na variedade brasileira.

Nesse sentido, a atribuição de evento tonal inicial $(\mathrm{L}+) \mathrm{H}$ ou $\mathrm{H}(+\mathrm{L})$ ocorre quando tal evento tonal é associado a alguma sílaba pretônica de PW. Esse fenômeno só ocorre quando a PW tem no mínimo três sílabas pretônicas e é opcional. Toneli, Vigário e Abaurre (2014) destacam que esse fenômeno caracteriza o domínio da PW no PB, pois só ocorre nos limites desse domínio, não incluindo palavras funcionais que estejam adjacentes a uma PW. 
Toneli, Vigário e Abaurre (2014) e Toneli (2014) mostram também que, além do evento tonal inicial, o acento enfático, que é utilizado para destacar algo do discurso sem que haja ligação semântica de contraste, também tem a PW como domínio de aplicação, uma vez que pode ocorrer associado às sílabas pretônicas iniciais ou a sílaba tônica de PW. Nesse caso, a ocorrência de acento enfático caracteriza o domínio da PW no PB, sendo um bom diagnóstico.

Não foram reportados em minhas pesquisas casos em que o acento enfático é usado para destacar palavras funcionais. $\mathrm{O}$ que mostro na minha pesquisa de mestrado (TONELI, 2009) é a ocorrência de acento de foco corretivo associado a palavras funcionais em contexto frasal. Somente nesse contexto, as palavras funcionais, normalmente átonas, recebem o estatuto de PW por sozinhas formarem um I e por receberem acento principal de tal domínio.

Por fim, um último fenômeno a ser discutido e que também caracteriza o domínio prosódico em estudo é a regra que distribui PA a sílabas tônicas, já que esse fenômeno ocorre somente em sílabas acentuadas por acento primário (cf. FROTA e VIGÁRIO, 2000; TENANI, 2002; FERNANDES, 2007; TENANI e FERNANDES-SVARTMAN, 2008; VIGÁRIO e FERNANDES-SVARTMAN, 2010; FROTA ET AL, 2015; entre outros).

Fernandes (2007) afirma inicialmente que o domínio da PW no PB é o domínio relevante para a distribuição de PAs. Essa relevância é atestada estatisticamente em minha tese de doutorado (TONELI, 2014), pois há praticamente um PA por PWs que compõem o sintagma entoacional. Desse modo, as análises estatísticas mostram que a regra de distribuição de PAs no PB toma a PW como domínio de aplicando, sendo, portanto, caracterizador desse domínio no PB.

A ausência de atribuição de PAs às palavras funcionais, mesmo aquelas que recebem acento primário, é evidência de seu comportamento átono (TONELI, 2009; 2014). Isso já é mostrado e descrito na literatura por Selkirk (1995) para o inglês e Vigário (1999) para o PE.

É importante destacar que esses fenômenos autossegmentais podem ocorrer em prefixos átonos que fazem parte dos limites da $\mathrm{PW}$, já que se comportam como sílabas pretônicas, mas não em palavras funcionais como afirmado.

Em síntese, a presente seção mostrou fenômenos segmentais e autossegmentais que tomam a PW como domínio de aplicação e por consequência podem funcionar como diagnóstico de sua identificação, principalmente no que se refere à prosodização de afixos e de palavras funcionais, ou mesmo caracterizam esse domínio no PB.

\section{PROSODIZAÇÃO DE PALAVRAS FUNCIONAIS E LEXICAIS: A DEFINIÇÃO DE PW NO PB}

Com base na discussão dos fenômenos fonológicos que diagnosticam e que caracterizam a $\mathrm{PW}$ no $\mathrm{PB}$, analiso nesta seção a prosodização das palavras funcionais e lexicais em relação ao domínio PW com o intuito de defini-la. 
Destaco brevemente aspectos que mostram uma distinção fonológica da prosodização de afixos átonos em relação à prosodização de palavras funcionais também átonas.

Em relação aos afixos sufixais, estes alteram a posição do acento primário, aumentando o tamanho da palavra morfológica, como lógica + ismo $=$ logicismo, enquanto o mesmo não ocorre com palavras funcionais enclíticas, como em chamAva + se $=$ chamAva-se . Considera-se que os sufixos entram no léxico como sílabas átonas que serão incorporadas a uma PW, com exceção de sufixos como -zinho e-mente que, ao se associarem a um radical acentuado, mantêm os acentos primários que foram lhe atribuídos no nível lexical. Nesse caso, tais sufixos formam sozinhos PWs.

A regra de redução da pauta vocálica postônica também corrobora a análise de que os sufixos átonos incorporam-se a uma base lexical, formando junto a esta última uma única PW. Nesse caso a não redução vocálica da sílaba antes do sufixo mostra que esta não se comporta como final de $\mathrm{PW}$, por exemplo em $p \operatorname{Obr}[\mathrm{I}]$ $+-e z a=\operatorname{pobr}[e ́] z a$. No caso da ocorrência de palavras funcionais após alguma palavra lexical, a regra de redução vocálica da postônica se mantém, como em $p E d[I]+t[I]=p E d[I]+t[I]$, atingindo também a vogal da palavra funcional, e isso mostra que a palavra funcional não se comporta como sufixo.

Em l[o']gica + -ismo $=$ l[o]giclsmo, nota-se a regra de redução da pauta pretônica quando há a inserção de sufixo, mas não quando há palavra funcional após o verbo, como em $l[\varepsilon] v a+t e=l[\varepsilon] v a-t e$. Nesse caso, essa regra também corrobora a análise de que a palavra funcional não faz parte da PW como o sufixo faz.

Há o fato de algumas regras fonológicas segmentais afetarem apenas afixos, como no caso da inserção de glide para quebrar o hiato que ocorre em sufixos, mas não palavras funcionais enclíticas, como em $c r E i o$ vs $d \hat{E}-o / *$ deio.

Diante disso, no caso dos sufixos, na minha tese de doutorado (TONELI, 2014), baseando-me em outras análises já propostas para o PB, assumo que os sufixos unem-se à base por meio da incorporação dentro do domínio da $\mathrm{PW}$ ainda no léxico, não havendo fronteira prosódica entre a base morfológica e o sufixo. Essa análise é fortificada pelo fato de os segmentos à direita da base lexical não se comportarem como final de $\mathrm{PW}$ e os segmentos que iniciam os sufixos não se comportarem como início de PW.

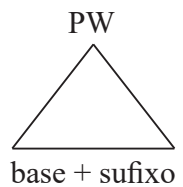

Em relação à diferença entre prefixos e palavras funcionais, a redução da pauta vocálica pode afetar palavras funcionais átonas que estão antecipando uma palavra lexical, como em $d[I] \operatorname{manh} \tilde{A}$, mas não prefixos átonos, como em *pr[I] concEIto, enquanto a regra de harmonia vocálica e a assimilação de nasalidade afetam apenas prefixos, mas não palavras funcionais átonas, como exemplificado na seção anterior. 
Contudo, apesar de que tanto afixos quanto palavras funcionais átonas sejam prosodizadas no léxico como sílabas átonas, assumo em minha pesquisa de mestrado e de doutorado (TONELI, 2009; 2014) que tais elementos se unem a uma PW em níveis distintos, ou seja, os afixos se unem a PW no nível lexical, enquanto as palavras funcionais unem-se a PW no nível pós-lexical.

No caso dos prefixos, assumo juntamente com Schwindt (2000) que o que ele chama de prefixos legítimos (PLs) são sílabas pretônicas que se unem a uma PW pronta no léxico, formando uma única PW no nível lexical, como apresentado em 4 .

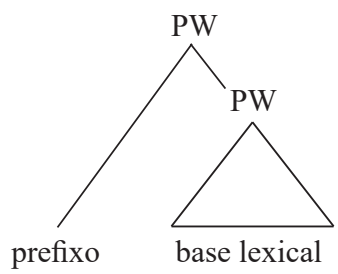

Além do acento primário, outros fenômenos prosódicos que colaboram com essa análise são a não neutralização da átona final do prefixo, como em $r[e] l e m b r A r \sim * r[I] l e m b r A r$, mas sim em $t[e]$ lembrAr $\sim t[I]$ lembrAr, e a assimilação de nasalidade, como em an+alfabEto $=$ analfabEto, mas não em com Amor * *omÃmor.

$\mathrm{O}$ que pode ser sintetizado em relação à prosodização de afixos no $\mathrm{PB}$ é que estes integram uma PW ainda no componente lexical, já que sofrem regras fonológicas típicas desse domínio.

Em relação à prosodização de palavras funcionais, algumas análises têm proposto que são inseridas diretamente no componente lexical sem sofrer antes processos lexicais (cf. KAISSE e SHAW, 1985, p. 9). Já Inkelas (1990, p. 241), por exemplo, sugere que palavras funcionais átonas não possuem propriedades atribuídas às palavras plenas no componente lexical, isso porque não sofrem regras lexicais.

Vigário (2003) ressalta, sobretudo, o fato de as palavras funcionais átonas não terem propriedades de $\mathrm{PW}$ lexicais, assim como notado por Inkelas, já que a elas falta acento primário, estando as vogais aptas a sofrer redução vocálica, além de não estarem sujeitas a generalizações fonotáticas a que PWs estão.

As evidências fonológicas discutidas na seção anterior mostraram que no PB há um conjunto de palavras funcionais que se comportam prosodicamente como sílabas átonas, sendo processadas no léxico como tal. Entretanto, há evidências que sugerem que não se comportam prosodicamente como afixos, não formando uma PW junto ao seu hospedeiro no léxico.

Entretanto, em relação ao modo como são prosodizadas, que também pode variar entre as línguas, assim como já proponho em meus trabalhos (TONELI, 2009; 2014), assumo no presente trabalho que as palavras funcionais destituídas de acento primário no nível lexical do PB entram no pós-léxico como sílabas átonas para serem prosodizadas junto a uma $\mathrm{PW}$. 
Essa análise é sustentada por outras, como a de Bisol (2005) e Brisolara (2008), as quais mostram que tais palavras se unem a um hospedeiro acentuado no nível pós-lexical. O principal argumento utilizado para tal análise é o fato de tais palavras átonas nesta variedade de português estarem sujeitas a regras de aplicação variável, típicas do componente pós-lexical, como sândi vocálico, tapping, vozeamento da fricativa, redução vocálica e semivocalização.

Especificamente em relação a processos de sândi vocálico externo, Tenani (2002) afirma que, quando a sequência de duas vogais iguais ocorre no nível pós-lexical, ou seja, em fronteira de PWs, a aplicação da DG é bloqueada se a segunda vogal é tônica ou se ambas forem tônicas. Entretanto, quando a sequência envolve palavra funcional átona e $\mathrm{PW}$, o processo ocorre, independentemente de a vogal inicial de PW ser átona ou tônica, como pode ser observado em do Ônibus < dÔnibus, me esqueci $<$ mesquEci e se está < sestÁ.

Embora a DG ocorra também dentro de PW, como em co+operAr > cooperAr $\sim$ coperAr, como descrito por Schwindt (2000), ela reforça a análise de que a palavra funcional átona comporta-se como sílaba átona no componente lexical.

A ditongação (DT) também é implementada independentemente de a vogal seguinte ser átona ou tônica, quando a sequência envolve palavras funcionais átonas, como em se Ele $<$ siEle, o Ônibus $<$ uÔnibus e me aguARde $<$ miaguArde. Convém destacar que, nos exemplos apresentados, a DT só ocorre quando as vogais /e, o/ forem alçadas a $[\mathrm{I}, \mathrm{U}]$. Apesar de ser um processo que não tem restrição quanto à fronteira prosódica, podendo ocorrer inclusive dentro de PW, a sua ocorrência na sequência palavra átona + hospedeiro mostra a natureza pós-lexical dessa união.

Em relação à redução vocálica no $\mathrm{PB}$, o fato de ocorrer independentemente de as palavras funcionais estarem à direita ou à esquerda de PW é evidência do comportamento delas como sílabas átonas, assim como ocorre com as sílabas átonas em final de palavras lexicais, como em $\operatorname{chAv}[\mathrm{I}]$ e $f A t[\mathrm{v}]$.

O fato de essa regra não ter aplicação obrigatória mostra que é um fenômeno pós-lexical que atinge palavras funcionais átonas, corroborando a análise de que as palavras funcionais são prosodizadas no pós-léxico junto ao hospedeiro, diferentemente dos afixos.

Além das evidências apresentadas de que a prosodização da sequência palavra funcional átona e hospedeiro ocorre no pós-léxico, a palatalização de /t, $\mathrm{d} /$, o vozeamento da fricativa /s/ e o tapping, como, respectivamente, em $d[3 i]$ manhÃ, a[z]menInas e po[r] Amor, reforçam tal análise por serem processos variáveis. Nesse caso, tais processos vão colaborar para a argumentação de que as palavras funcionais são prosodizadas junto ao hospedeiro no pós-léxico.

Por outro lado, o bloqueio da regra de assimilação de nasalidade que ocorre normalmente dentro de $\mathrm{PW}$, como em bãnÃna, por não afetar palavras átonas, como em ele *ã $n A n a$, é um dos principais fenômenos que sustentam a análise de que palavras funcionais átonas não são sílabas pretônicas de uma PW, mas sílabas átonas que se unem a uma PW no nível pós-lexical.

Embora as palavras funcionais átonas sejam prosodizadas como sílabas átonas no léxico, assim como os afixos, é assumido no presente trabalho que vão se unir junto a uma PW pronta no pós-léxico, diferentemente do que ocorre com os afixos, como já mostrado acima em 3 e 4 . 
Essa análise, entretanto, viola o princípio da recursividade, na formação de uma PW, mesmo que seja assumido que o item é uma PW pós-lexical, análise já proposta por Vigário $(1999,2003)$ que propõe que as palavras funcionais formam junto com o hospedeiro uma PW recursiva no PE.

Outra possibilidade de análise é assumir que essa adjunção ocorre em um nível superior, como $\varphi$, abrindo mão da violação da restrição de recursividade e mantendo a violação da restrição de exaustividade, já que a palavra funcional é prosodizada como sílaba átona que se une diretamente a uma PW num domínio mais alto que PW.

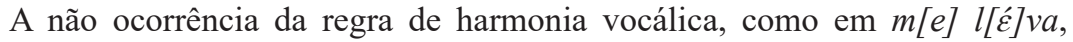
como ocorre dentro de $\mathrm{PW}$ em $p[\varepsilon] r[\varepsilon] r[\varepsilon ́ \varepsilon] c a$, é uma evidência de que a palavra funcional não faz parte de PW do mesmo modo como ocorre com prefixos e sílabas pretônicas.

Por outro lado, o bloqueio da haplologia em sequências como [[cUrso]

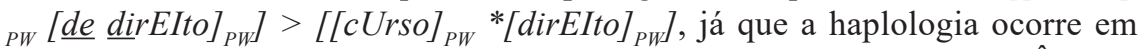
sequências que envolvem PWs dentro de $\varphi$, como em [[faculdAde] ${ }_{P W}$ [din $\hat{A}$ mica]

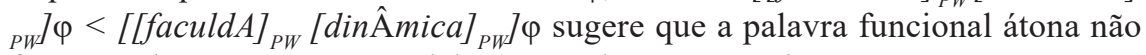
faz parte de uma PW como sílabas pretônicas e postônicas.

Devido ao fato de não haver argumentos claros do domínio em que a adjunção de palavra funcional átona a uma PW ocorre no PB, é assumido que a palavra funcional é prosodizada como sílaba átona no léxico e, no pós-léxico, agrega-se a PW pronta como sílaba átona e junto a ela forma uma PW pós-lexical. Destaca-se que afixos e palavras funcionais são prosodizados em diferentes níveis da gramática em relação ao domínio PW, pois os primeiros formam uma PW no léxico e os segundos, no pós-léxico, como afirmado.

Essa análise para a prosodização das palavras funcionais, entretanto, é uma questão que fica aberta para discussões futuras e contra-argumentação, mesmo porque há propostas na literatura para outras línguas de que não há domínio específico para essa adjunção ocorrer, podendo a palavra funcional átona se juntar a domínios distintos dependendo da língua e do contexto fonológico. Por ora, considerando o fato de a recursividade ser um recurso ativo nas línguas, no caso do PB no nível sintático, parece menos custoso à gramática do $\mathrm{PB}$ a violação de recursividade no nível fonológico do que de exaustividade.

Em vista do apresentado sobre a prosodização de afixos e de radicais lexicais, foi destacado ao longo desta seção que no PB algumas unidades morfológicas são unidas no léxico, formando (i) uma única PW com um radical e uma vogal temática, por exemplo, $[\mathrm{cas}+a]_{P W}$, (ii) uma $\mathrm{PW}$ com um sufixo incorporado à esquerda de $\mathrm{PW}$, por exemplo, alegrar + mento $=[\text { alegramento }]_{P W}$, e (iii) uma $\mathrm{PW}$ com um prefixo adjungido à direita de uma $\mathrm{PW}$, por exemplo, des + honesto $=[\text { desonesto }]_{P W}$.

No caso de palavras funcionais, foi mostrado que são prosodizadas como sílabas átonas, no léxico e estas se unem a uma PW pronta no pós-léxico (iv) uma


como em [falávamo $]_{P W}+[\text { nos }]_{\sigma}$.

Assim, para derivar a prosodização de elementos que incluem palavras formadas por afixação, assumo a generalização proposta por Vigário (2003) para a definição de PWs formadas no léxico. 
(5) Domínio da PW lexical: O domínio da PW lexical inclui um radical mais afixos tanto à direita quanto à esquerda.

Para, então, incluir a prosodização de palavras funcionais átonas junto a uma PW no nível pós-lexical, assumo a definição de Vigário (2003) para PW no nível pós-lexical, a qual inclui dois componentes: um que define o modo como PWs lexicais são relacionadas à estrutura prosódica construída pós-lexicalmente e outra que define a informação sintática referida no mapeamento entre estrutura sintática e estrutura prosódica no nível de PW.

(6) Domínio da PW pós-lexical:

a. As fronteiras de uma PW lexical são pós-lexicalmente projetadas.

b. A Lex ${ }^{0}$ é mapeada até uma PW.

Em síntese, este artigo cumpriu seu objetivo que era mostrar os processos fonológicos que diagnosticam e caracterizam a PW como domínio de aplicação de regras fonológicas no PB, além de analisar a prosodização de elementos morfológicos, no caso de palavras lexicais formadas por afixação e de palavras funcionais como PWs ou como sílabas átonas para então se chegar a uma definição de PW na variedade brasileira como proposta.

Por ora, o presente trabalho, por não ignorar o fato de que a prosodização de palavras funcionais átonas pode variar de língua para língua e de que não há argumentos robustos para uma análise definitiva para a prosodização de tais palavras, mantém aberta à contra-argumentação a análise aqui proposta.

\section{CONSIDERAÇÕES FINAIS}

O objetivo do presente artigo era apresentar uma definição para o domínio da PW no PB. Para isso, revisei e discuti os principais trabalhos realizados no PB sobre a fonologia da palavra e os preceitos teóricos seguidos para a definição de PW para mostrar os contributos iniciais do assunto que respaldam a definição aqui proposta.

Outra contribuição das minhas pesquisas foi trazer à literatura do PB uma sistematização dos fenômenos segmentais, acentuais e entoacionais que identificam e caracterizam a PW no PB como domínio de aplicação de regras fonológicas.

A discussão sobre a prosodização de um conjunto de unidades morfológicas, lexicais e funcionais, como PWs, dentre elas todas as palavras lexicais e algumas palavras funcionais, ou como sílabas átonas, como no caso de algumas palavras funcionais, também é uma contribuição de minhas pesquisas. Desse modo, o presente artigo definiu os meios de identificar a prosodização de elementos morfológicos em relação ao domínio $\mathrm{PW}$, sejam as palavras funcionais como sílabas átonas ou como PWs, sejam os afixos não acentuados, sejam os radicais mais afixos que formam PWs.

Desse modo, homenageio a professora Bernadete, pois esses contributos só puderam ser construídos com sua a orientação e também com o respaldo em seus trabalhos voltados a essa temática, além de sua experiência na pesquisa e na docência. 
A partir da presente reflexão sobre a prosodização das palavras funcionais, destaco ainda alguns apontamentos para pesquisas futuras. Há um domínio prosódico exclusivo para a adjunção das palavras funcionais átonas no PB? Há evidências de que a palavra funcional átona forma uma estrutura recursiva pós-lexical, violando o princípio da recursividade?

Em relação aos fenômenos fonológicos que servem de diagnóstico para a PW no PB ou para caracterizar tal domínio, há outras variedades de PB que mostram comportamentos distintos da aplicação de regras entoacionais (distribuição de PAs, de evento tonal inicial e de acento enfático), visto que os estudos realizados não englobam todas as regiões do Brasil? Se houver, podem corroborar as análises apresentadas para o domínio da PW no PB?

Essas são algumas questões a serem investigadas em trabalhos futuros.

\section{REFERÊNCIAS BIBLIOGRÁFICAS}

ABAURRE, M. B. e FERNANDES-SVARTMAN, F. R. Secondary stress, vowel reduction and rhythmic implementation in Brazilian Portuguese. In: Leda Bisol e Claúdia R. Brescancini (Orgs.). Contemporary Phonology in Brazil. Newcastle: Cambridge Scholars Publishing, 2008, pp. 54-83, 2008.

ABAURRE, M. B e PAGOTTO, E. G. Nasalização fonética e variação. In: Maria Bernadete Marques Abaurre (Org.). A construção fonológica da palavra. 1ed. São Paulo: Contexto, 2013, v. 1, pp. 141-164.

ABAURRE, M. B. M.; PAGOTTO, E. G. Nasalização No Português do Brasil.. In: Ingedore Grunfeld Villaça Koch. (Org.). Gramática do Português Falado VI. $1^{\mathrm{a}}$ ed. Campinas, SP: Editora da Unicamp, 1996, v. 1, pp. 495-526.

ABAURRE, M. B. M.; SANDALO, F. Acento secundário em duas variedades de português: uma análise baseada na OT. In: Gabriel A. Araújo. (Org.). O acento em português: abordagens fonológicas. São Paulo: Parábola Editorial, 2007, pp. 145-167.

BISOL, L. Mattoso Câmara Jr. e a palavra prosódica. Delta, 20: especial, 2004, pp. 59-70.

BISOL, L. O clítico e seu hospedeiro. Letras de hoje. Porto Alegre. V. 40, nº 3, 2005, pp. 163-184.

BOOIJ, G. Cliticization as Prosodic Integration: The case of Dutch. The Linguistic Review 13, 1996, pp. 219-242.

BRISOlARA, L. B. A prosodização dos clíticos pronominais no sul do Brasil: uma análise variacionista com base na regra de elevação da vogal átona /e/. Dissertação de Mestrado. 2004. Universidade Católica de Pelotas, Pelotas, 2004.

BRISOLARA, L. Os clíticos pronominais do Português Brasileiro e sua prosodização. Tese de Doutorado. 2008. Pontifícia Universidade Católica do Rio Grande do Sul, Porto Alegre, 2008.

CAMARA Jr, M. Estrutura da Língua Portuguesa. Rio de Janeiro, Petropólis, 1970.

CAMARA Jr, M. História e estrutura da Lingua Portuguesa. Rio de Janeiro. Padrão, 1975.

CAMARA Jr, M. Problemas de Linguística Descritiva. Petrópolis, RJ: Vozes, 1975 
COOK, V. J. e NEWSON, M. Chomsky's Universal Grammar - an introduction (second edition). Oxford: Blackwell Publishers, 1996.

COLlishONN, G. Um estudo do acento secundário em português. 1993. Dissertação de Mestrado. Universidade Federal do Rio Grande do Sul, Porto Alegre, 1993.

FERNANDES, F. R. Ordem, focalização, e preenchimento em Português: sintaxe e prosódia. 2007. Tese de Doutorado. Instituto de Estudos da Linguagem. Universidade Estadual de Campinas, Campinas, 2007.

FERNANDES-SVARTMAN, F. R. 2009 Acento secundário, atribuição tonal e ênfase em português brasileiro (PB). Estudos Lingüísticos (São Paulo), v. 38, 2009, pp. 47-58.

INKELAS, S. Prosodically constrained syntax. In: INKELAS, S. e ZEC, D. (Orgs.). The phonologysyntax connection. Cambridge: The University of Chicago Press, 1990.

LEIRIA, L. L. Em busca da palavra prosódica. 2000. Tese de doutorado. Pontifícia Universidade Católica do Rio Grande do Sul, Porto Alegre, 2000.

MIOTO, C.; SILVA, M. C. F.; LOPES, R. E. V. Novo Manual de Sintaxe. Florianópolis, Insular, 2004.

NESPOR, M.; VOGEL, I. Prosodic Phonology. Dordrecht: Foris Publications, 1986.

SCHWINDT, L. C. O prefixo do português brasileiro: análise morfofonológica. 2000. Tese de Doutorado. Rio Grande do Sul: PUCRS, 2000.

SELKIRK, E. The prosodic structure of function words. In: BECKMAN, J. ET AL. Papers in Optimality Theory. Amherst, Mass.: GLSA University of Massachussetts Occasional Papers, 18, 1995, pp. 439-469.

TENANI, L. E. Domínios prosódicos no Português. 2002. Tese de Doutorado. Universidade Estadual de Campinas, Campinas. 2002.

TONELI, P. M. A palavra prosódica no Português Brasileiro: o estatuto prosódico das palavras funcionais. 2009. Dissertação de Mestrado. Universidade Estadual de Campinas. Campinas, 2009.

TONELI, P. M. A palavra prosódica no Português Brasileiro. 2014. Tese de doutotrado. Universidade Estadual de Campinas. Campinas, 2014.

TONELI, P. M.; VIGARIO, M.; ABAURRE, M. B. M. Distinguishing emphatic and Prosodic Word inital stresses: evidences from Brazilian Portuguese. In: Proceedings of the 4th International Symposium on Tonal Aspects of Languages, Nijmegen. 4th International Symposium on Tonal Aspects of Languages, 2014.

VIGÁRIO, M. On the prosodic status of stressless function words in European Portuguese. In: Studies on the phonological word. Current Issues in Linguistic Theory. Amsterdam/ Philadelphia, 1999.

VIGÁRIO, M. The Prosodic Word in European Portuguese. Berlin/New York: Mouton de Gruyter, 2003. (Tese de Doutorado. Lisboa: Universidade de Lisboa, 2001). 